\title{
A taxa de câmbio e os ajustes no saldo da balança comercial brasileira: uma análise setorial da Curva J
}

Exchange rate and adjustments in the Brazilian trade balance: a sectoral analysis of the $J$ Curve

Hélio Sousa Ramos Filho

Universidade Federal da Paraíba

Maysa Evellyn Porfirio Ferreira

Universidade Federal da Paraíba

\section{Abstract}

This paper aims to assess whether or not the phenomenon J Curve for 19 sectors of the Brazilian manufacturing industry. Data were collected from the Ministry of Development, Industry and Foreign Trade (MDIC) and the variables used were the Effective Real Exchange Rate, GDP of Brazil, World GDP corresponding to the period 19962012. Methodology used was the ARDL cointegration model proposed in Pesaran et al. (2001). The results suggest that only four sectors - Aeronautics and Aerospace, Wood and its Products and Pulp and Paper, NE Manufactures and Recycled Goods - seem to exhibit the effect incomplete J Curve. Moreover, the sector of Naval Construction and Repair, presents incomplete evidence and reversed the curve phenomenon J. Therefore, the occurrence of incomplete Curve $\mathrm{J}$ is not associated with the degree of technological intensity sectors.

\section{Keywords}

J Curve; cointegration test; trade balance; exchange rate.

JEL Codes F14; C22; F31.

\section{Resumo}

Este artigo buscou avaliar a existência do fenômeno da Curva J para 19 setores da indústria de transformação brasileira segmentados pelo nivel tecnológico de indústrias da alta, média-alta, média-baixa e baixa tecnologia. Os dados foram coletados no Ministério do Desenvolvimento, Indústria e Comércio Exterior (MDIC). Foram utilizadas as seguintes variáveis: taxa do câmbio real efetiva, PIB do Brasil, PIB Mundial referente ao período de 1996 a 2012. A metodologia empregada foi o modelo Autorregressivo de Defasagens Distribuídas (ARDL) com cointegração proposto em Pesaran et al. (2001). Os resultados obtidos sugerem que apenas quatro setores- Aeronáutica e Aeroespacial (alta intensidade tecnológica); Madeira e seus Produtos, Papel e Celulose; e Produtos Manufaturados N. E. e Bens Reciclados (baixa intensidade tecnológica) - parecem exibir o efeito Curva J incompleto. O setor da Construção e Reparação Naval (média-baixa intensidade tecnológica) apresenta evidência incompleta e invertida do fenômeno Curva J. Portanto, a ocorrência da Curva Incompleta parece não estar associada ao grau de intensidade tecnológica dos setores.

\section{Palavras-chave}

Curva J; teste de cointegração; saldo da balança comercial; taxa de câmbio.

Códigos JEL F14; C22; F31. 


\section{Introdução}

Nas últimas décadas, a economia brasileira passou por diversas mudanças na condução da política comercial e cambial. Observou-se desde redução das tarifas de importações até alteração do regime cambial, cujos reflexos podem ser percebidos na dinâmica do saldo da balança comercial. Segundo dados do Instituto de Pesquisa Econômica Aplicada (IPEA), no ano de 2004, o saldo da balança comercial brasileira registrou US\$33,37 bilhões, e,no ano de 2013, US $\$ 2,56$ bilhões. Significa dizer que, durante esse período, o saldo reduziu em mais de $92 \%$. Vários fatores podem ter contribuído para tal desempenho, dentre eles, a crise internacional, o crescimento da economia brasileira e o comportamento da taxa de câmbio.Segundo dados do IPEA, este último apresentou depreciação de aproximadamente $26,26 \%$ na última década.

A relação entre o saldo da balança comercial e a taxa de câmbio é uma das relações mais bem estabelecidas na teoria econômica. Argumenta-se que a depreciação cambial resulte em aumentos nas exportações e reduções nas importações, o que melhora o saldo da balança comercial. Contudo, de acordo com a condição Marshall-Lerner, essa situação só ocorre se a soma das elasticidades das exportações e importações for maior que a unidade. Lobo (2007) apontam que existem situações em que há um retardamento do efeito esperado em curto prazo. Graças a fatores institucionais e burocráticos do país, tais efeitos somente são observados em longo prazo. Magee (1973) denominou esse fenômeno de Curva J, que seria a resposta lenta da balança comercial em relação a dada variação na taxa de câmbio.

Rose e Yellen (1989) propõem um procedimento que consiste na identificação do referido fenômeno com base nas elasticidades de curto e longo prazos e que foi adotado nesta pesquisa. A evidência empírica internacional da Curva J foi confirmada por vários pesquisadores em diferentes países e diferentes níveis de desagregação dos dados, por exemplo, por Gupta-Kappor e Ramakrishnan (1999), no Japão; Narayan (2004), na Nova Zelândia; Bahmani-Oskooee e Harvey (2006), na Malásia; Bahmani-Oskooee e Kutan (2009), na Bulgária; Shahbaz et al. (2011, 2012), no Paquistão; Bahmani-Oskooee e Harvey (2012), em Cingapura, na Croácia e na Rússia; Kyophilavong, Shahbaz e Uddin (2013), em Laos, e Wijeweera e Dollery (2013), na Austrália. Em contrapartida, Wilson (2001) e Bahmani-Oskooee e Wang (2006) não encontraram evidências do fenô- 
meno da Curva J em relação a Cingapura e Malásia, Coreia do Sul e a China, respectivamente.

No tocante ao Brasil, os resultados não parecem consensuais. Por um lado, Lobo (2007), Mendes e Piza (2007) e Vasconcelos (2010), utilizando dados agregados, não encontraram evidências de uma Curva J. Por outro lado, Pena et al. (2011), além de Sonaglio, Scalco e Campos (2010), confirmam a Curva J, também fazendo uso de dados desagregados.

Assim, o principal objetivo deste estudo é testar a evidência da Curva J por setores industriais, contribuindo com a literatura existente em três aspectos. Primeiro, constitui-se num esforço de estudar a relação entre taxa de câmbio e saldo da balança comercial durante o período recente (19962012), de depreciação cambial, sem aparente resposta positiva do saldo comercial. Quanto ao segundo aspecto, a análise realizada será desagregada por setores industriais. Terceiro, o modelo Autorregressivo de Defasagens Distribuídas (ARDL) com cointegração proposto por Pesaran et al. (2001) será utilizado no presente artigo por permitir captar a dinâmica de curto e longo prazos do saldo da balança comercial, em resposta às mudanças na taxa de câmbio. A escolha foi baseada na literatura internacional, que considera a referida abordagem como uma mais adequada.

Este artigo está estruturado da seguinte maneira: a seção 2 dedica-se à revisão da literatura empírica, com apresentações sucintas de algumas pesquisas nacionais e internacionais sobre o tema; na terceira seção, serão exibidos o modelo e a metodologia utilizados, e, na quarta seção, serão apresentados os resultados e as discussões. Por fim, a última seção consiste na conclusão.

\section{Revisão da literatura}

Esta seção visa apresentar breve revisão da literatura empírica internacional e nacional acerca do fenômeno Curva J. Por exemplo, Bahmani-Oskooee e Kantipong (2001) testaram a hipótese da Curva J utilizando dados comerciais bilaterais desagregados entre a Tailândia e os cinco maiores parceiros comerciais (Alemanha, Japão, Cingapura, Reino Unido e EUA) durante o primeiro trimestre de 1973 ao último de 1997.

Por sua vez, Bustamante e Morales (2009) testaram a condição de Marshall-Lerner e da Curva J na economia peruana, entre os anos 1991 e 2008, 
com o auxílio da metodologia de Vetores Autorregressivos Cointegrados (VEC). Os resultados revelaram que o fenômeno da Curva J não é encontrado, mas confirmaram a existência da condição de Marshall-Lerner. A principal conclusão foi de a que os fatores determinantes, no longo prazo, da balança comercial do Peru, são a taxa de câmbio real e a renda mundial.

Por outro lado, Bahmani-Oskooee e Ardalani (2007) testaram a dinâmica da Curva J com utilização de dados mensais de exportação e importação de 66 indústrias dos EUA, durante o período de janeiro de 1991 a agosto de 2002. Os autores identificaram, no mínimo, dois atrasos e, no máximo, dez defasagens de resposta do saldo nas alterações na taxa de câmbio. Diante disso, confirmaram a existência do efeito Curva J apenas em seis das indústrias analisadas.

Wang, Lin e Yang (2012) avaliaram a relação entre balança comercial e taxa de câmbio real, envolvendo a China e seus 18 principais parceiros comerciais com a utilização de um conjunto de dados em painel no período compreendido entre 2005 e 2009. Ao empregar a metodologia de dados em painel, os resultados mostraram que o fenômeno da Curva J é invertido. É importante ressaltar que a valorização do RMB, a moeda chinesa, provocaria deterioração da balança comercial da China, confirmando o argumento de que a China, de fato, controla a taxa de câmbio para retardar a apreciação razoável de sua moeda. Somado a esse processo, foi aplicado o procedimento de cointegração para identificar a relação de longo prazo entre o RMB e o comércio chinês em equilíbrio, cujo resultado foi um efeito negativo, em longo prazo, quanto à valorização do RMB na balança comercial. Constatou-se quea Curva J incompleta para três dos 18 parceiros comerciais, incluindo os EUA, o Reino Unido e o Japão. Portanto, os achados corroboram a teoria.

Com a utilização de dados de exportações e importações setoriais anuais, Soleymani e Saboori (2012) testaram a dinâmica da Curva J, na análise da balança comercial com relação à taxa de câmbio, além de outras variáveis, entre o comércio bilateral, Malásia e Japão, durante o período de 1974 a 2009. Considerando 67 indústrias, e com o auxílio da abordagem de teste de limites para cointegração e modelagem de correção de erros,o estudo apresentou que apenas 22 dessas confirmaram o efeito da Curva J.

Quanto às evidências da Curva J no Brasil, Lobo (2007), ao analisarem o período compreendido entre 1980 e 2005, chegaram a resultados que não comprovam o efeito Curva J. Usando três diferentes testes, concluíram que 
as rendas externa e interna são determinantes importantes para explicar o saldo da balança comercial, independentemente de resultar em depreciação ou apreciação de grande duração de tempo descrito por elevadas alterações da taxa de câmbio.

Mendes e Piza (2007), ao utilizarem a metodologia de Vetores Autorregressivos (VAR), não encontraram resultados que comprovassem a hipótese da Curva J. Durante o período pesquisado, entre 1990 e 2007, encontraram suporte apenas para a condição Marshall-Lerner. Segundo eles, o períodos e tratou de uma fase com várias alterações na economia brasileira em razão das modificações importantes nos cenários político e econômico e que pode ter influenciado os resultados.

Por sua vez, Sonaglio, Scalco e Campos (2010) destacaram que seis dos 21 setores analisados durante o período de 1994 a 2007 respeitaram a condição de Marshall-Lerner, sendo que dez setores estudados corroboraram com a primeira fase da hipótese da Curva J, ocorrendo então a depressão abrupta em momento inicial. Contudo, dois desses exibem superávit na balança comercial, em dado momento durante o período analisado, isto é, confirmam o efeito da Curva J. Os autores sugerem a necessidade de análises individuais para cada setor, respeitando suas características.

Vasconcelos (2010) analisou o comportamento de curto e longo prazos da balança comercial brasileira quanto às variações na taxa de câmbio, considerando as trocas comerciais entre o Brasil e os EUA, o MERCOSUL, a União Europeia e o Resto do Mundo, durante o primeiro trimestre de 1990 e o segundo trimestre de 2009. Os testes realizados sugerem a validação da condição Marshall-Lerner em relação ao MERCOSUL e aos EUA, e que, para esses, a balança comercial brasileira é elástica em relação às alterações na taxa de câmbio. Apenas para os EUA é que se constata a influência de outras variáveis. A Curva J não é confirmada quanto à relação bilateral em relação ao MERCOSUL e aos Estados Unidos.

Pena et al. (2011) dissecaram os efeitos das oscilações da taxa de câmbio em relação ao comportamento das exportações, importações e do saldo da balança comercial, no período compreendido entre 1992 e 2003. Foi observado, no ano de 1995, o chamado efeito Histerese, ${ }^{1}$ além de deterioração no saldo da balança comercial brasileira. As relações entre taxa de câmbio e transações correntes no período confirmaram a existência da Curva J 1 Segundo Frankel, Caves e Jones(2001, p. 305), "histerese" é o termo utilizado para descrever tais reações de difícil reversão. 
por causa dos coeficientes das elasticidades das demandas das exportações (positivo, elástica) e importações (negativo, inelástica), além das ações governamentais, por meio de políticas econômicas que reduzissem a taxa de câmbio para favorecer o combate à inflação.

Diante do exposto, as análises de uma Curva J em relação ao Brasil não proporcionaram resultados consensuais. Mesmo em estudos que contenham alguma confirmação do efeito Curva J, há mais resultados que não evidenciam a dinâmica da Curva J, do que o contrário.

\section{Modelo e metodologia}

\subsection{Modelo teórico}

Para Frankel, Caves e Jones (2001), as exportações líquidas são definidas pela diferença entre as exportações e as importações, como segue:

$$
B C=X\left(\varepsilon, Y^{*}\right)-M(\varepsilon, Y)
$$

Onde: $B C$ corresponde ao saldo da balança comercial;

$X$ são as Exportações;

$\varepsilon$ é a taxa de câmbio;

$Y^{*}$ é a renda externa;

$M$ são as importações;

$Y$ é a renda interna.

Supondo que o comércio é equilibrado, $X=M$, e que uma redução em $\varepsilon$ provoca aumentos em $\mathrm{BC}$, o saldo será positivo se:

$$
(X \varepsilon-M-\varepsilon M \varepsilon)>0
$$

Admitindo que a taxa de câmbio real e nominal são iguais, graças à PPC, e utilizando o artifício de definir $\mathrm{M}=\mathrm{X} / \varepsilon$, encontra-se a chamada condição Marshall-Lerner:

$$
\frac{\varepsilon}{X} X \varepsilon+\left|\frac{\varepsilon}{N} N \varepsilon\right|>1
$$


A equação estabelece que uma depreciação da taxa de câmbio real melhora o saldo da balança comercial quando a soma das elasticidades das exportações e das importações for maior que um. Contudo, a condição pode ser violada. Isso porque, em determinados casos, por causa de atrasos, muitas vezes na percepção de alterações de fatores da economia, a resposta do saldo da balança comercial no curto prazo é de deterioração. Isto é, a dinâmica do saldo dando origem ao fenômeno da Curva J.

Segundo Frankel, Caves e Jones (2001), em um primeiro momento, após depreciação real da moeda, o saldo da balança comercial se deteriora. Em um segundo momento, o efeito elasticidade torna-se elevado, o que favorece a balança comercial. Em um terceiro momento, a condição Marshall-Lerner volta a ser respeitada, e o saldo torna-se positivo. Ao final, é evidente que o comportamento do saldo da $\mathrm{BC}$, em resposta às mudanças na taxa de câmbio, forma o desenho da letra J, sendo então denominada de Curva J. Portanto, o fenômeno Curva J requer evidência de uma elasticidade do Saldo da BC em relação à taxa de câmbio real negativa no curto prazo e positiva no longo prazo (Rose; Yellen, 1989).

\subsection{Modelo empírico}

O modelo empírico baseia-se em Oskooee e Kantipong (2001) e em Rose e Yellen (1989), e a forma reduzida da equação 1 é:

$$
B C=f\left(Y, Y^{*}, \varepsilon\right)
$$

Onde: $M$ são as importações do Brasil;

$Y$ é a renda interna;

$P_{m}$ é o preço relativo nacional.

A especificação empírica da equação 4é:

$$
\operatorname{Ln} B C_{j t}=a+b \operatorname{Ln} Y_{B R t}+c \operatorname{Ln} Y_{j t}+d \operatorname{Ln} \varepsilon_{j t}+u_{t}
$$

Onde: $B C_{j t}$ é o saldoda balança comercial entre o Brasil e os países parceiros comerciais;

$Y_{B R}$, medida pelo Produto Interno Bruto (PIB) brasileiro; 


\section{$Y_{j}$ é o Produto Interno Bruto Mundial; \\ $\varepsilon_{j}$ é a taxa de câmbio real efetiva.}

Para capturar o efeito dinâmico de uma depreciação da taxa de câmbio real sobre o saldo da balança comercial, ou seja, o efeito Curva J, é necessária uma especificação que incorpore a dinâmica de curto prazo dentro do modelo de longo prazo (equação 5). Para tal finalidade, foi adotado o modelo Autorregressivo de Defasagens Distribuídas (ARDL) para cointegração desenvolvido por Pesaran et al. (2001). Esse método apresenta várias vantagens quando comparado a outros métodos de cointegração. Primeiramente, são evitados problemas de endogeneidade e de incapacidade de testar hipóteses sobre as estimativas dos coeficientes de longo prazo presentes no método de Engle-Granger. Segundo, os coeficientes de curto e longo prazos dos modelos são estimados simultaneamente. Terceiro, admite-se que todas as variáveis sejam endógenas. Quarto, a abordagem de Pesaran et al. (2001) testa a existência de cointegração sem a necessidade a priori de classificar as variáveis como I(0), I(1) ou conjuntamente I(0); logo, o método não requer testes de raiz unitária. ${ }^{2}$ Por fim, conforme Narayan (2004), as propriedades em pequenas amostras do método ARDL cointeração são superiores aos métodos de cointegração multivariada. Por essas razões, a literatura internacional vem utilizando essa abordagem para avaliar a existência do fenômeno Curva J.

A representação da equação 5 é formulada como segue:

$$
\begin{aligned}
& \Delta L n B C_{j, t}=\alpha_{0}+\sum_{\mathrm{i}=1}^{\mathrm{n}} \mathrm{b}_{i} \Delta \operatorname{LnB} C_{t-1}+\sum_{\mathrm{i}=1}^{\mathrm{n}} \mathrm{c}_{i} \Delta \operatorname{Ln} Y_{B R, t+i-1}+\sum_{i=1}^{n} d_{i} \Delta \operatorname{Ln} Y_{j, t-1} \\
& +\sum_{i=1}^{n} f_{i} \Delta \operatorname{Ln} \varepsilon_{j, t-1}+\delta_{1} \operatorname{LnB} C_{j, t-1}+\delta_{2} \operatorname{Ln} Y_{B R, t-1}+\delta_{3} \operatorname{Ln} Y_{j, t-1}+\delta_{4} \operatorname{Ln} \varepsilon_{j, t-1}+u_{t}
\end{aligned}
$$

A fim de testar a existência de uma relação de longo prazo, Pesaram et al. (2001) propuseram um teste $\mathrm{F}$ no qual avalia se $\delta_{1}=\delta_{2}=\delta_{3}=\delta_{4}=0$, independentemente de as variáveis serem $\mathrm{I}(0)$ ou $\mathrm{I}(1){ }^{3} \mathrm{O}$ teste $\mathrm{F}$ avalia a exclu-

2 Desse modo, no caso de quebras estruturais introduzirem incerteza quanto à integração das variáveis, I(0) ou (1), o modelo ARDL com cointegração permanece válido, de acordo com Pesaran et al. (2001).

3 Esse teste $\mathrm{F}$ permite, através de valores críticos apropriados, interpretar que, se a estatística F calculada se encontra acima do valor superior apropriado ao modelo, a hipótese nula é rejeitada, indicando que há cointegração entre as variáveis observadas, ou seja, que pode existir 
são do mecanismo de correção de erro (MCE) na equação 6 , formado pelas variáveis defasadas do PIB do Brasil $\left(\mathrm{Y}_{\mathrm{BR}, \mathrm{t}-\mathrm{i}}\right)$, PIB Mundial $\left(\mathrm{Y}_{\mathrm{j}, \mathrm{t}-\mathrm{1}}\right)$ e taxa do câmbio real efetiva $\left(\varepsilon_{\mathrm{j}, \mathrm{t}-1}\right)$. $\bigcirc$ mecanismo de correção de erro (na equação ๑) é a seguinte equação de longo prazo:

$$
\delta_{1} \operatorname{LnB} C_{j, t-1}+\delta_{2} \operatorname{Ln} Y_{B R, t-1}+\delta_{3} \operatorname{Ln} Y_{j, t-1}+\delta_{4} \operatorname{Ln} \varepsilon_{j, t-1}
$$

A teoria econômica sugere que um aumento na renda doméstica (PIB Brasil) provoca redução no saldo da balança comercial; logo, espera-se que o coeficiente da variável PIB seja negativo. Por sua vez, elevações na renda mundial (PIB Mundial) estimulariam as exportações e aumentariam o saldo da balança comercial. Neste caso, o coeficiente esperado da variável PIB Mundial é positivo. Finalmente, o coeficiente esperado da taxa de câmbio real é positivo, haja vista que uma depreciação incentivaria o crescimento das exportações e desestimularia as importações no longo prazo.

Vale lembrar que o fenômeno Curva J requer evidência de uma elasticidade (coeficiente) do saldo da balança comercial (BC) em relação à taxa de câmbio real negativa no curto prazo e positiva no longo prazo (Rose; Yellen, 1989). Isto é, para confirmação da Curva J, a condição imposta é que coeficiente $\delta_{4}>0$ e $\sum_{\mathrm{i}=1}^{\mathrm{n}} f i<0$.

\subsection{Dados e informações}

Com base no modelo teórico já descrito, as variáveis utilizadas foram as seguintes: taxa do câmbio real efetiva, pesquisada no site do Banco Mundial. O PIB do Brasil e o PIB Mundial e encontradas no site das Nações Unidas sobre Comércio Além desses, foram coletadas informações sobre o saldo da balança comercial segmentadas pelo nível tecnológico de indústrias da alta, média-alta, média-baixa e baixa tecnologia no Ministério do Desenvolvimento, Indústria e Comércio Exterior (MDIC). Os dados são anuais, e, dada a disponibilidade, o período de estudo foi de 1996 a $2012 .{ }^{4}$

relação de equilíbrio de longo prazo.

4 A periodicidade foi definida com base na disponibilidade dos dados setoriais de exportação e importação do Ministério do Desenvolvimento, Indústria e Comércio Exterior (MDIC). Contudo, o uso de dados anuais restringe a possibilidade de identificar a Curva J para aqueles setores que respondam mais rapidamente às alterações na taxa de câmbio, ou seja, os setores que apresentem respostas de curto e longo prazos, em um período inferior a um ano, não 
A classificação setorial adotada seguiu o critério da Organização para a Cooperação e Desenvolvimento Econômico (OCDE). ${ }^{5}$

\section{Análise de resultados}

Inicialmente, foi utilizando o critério de informação de Akaike ${ }^{6}$ para a escolha dos modelos ARDL (Tabela 1). Isso posto, foram aplicados os testes de diagnósticos (Tabela 1): Autocorrelação, Forma Funcional, Normalidade e Heterocedasticidade para avaliar a especificação dos modelos.

Tabela 1 Escolha do modelo ARDL: Testes de Diagnóstico LM, 1996 - 2012

\begin{tabular}{|c|c|c|c|c|c|c|}
\hline 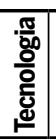 & $\begin{array}{r}\text { Setor/ } \\
\text { Modelo ARDL }\end{array}$ & $\begin{array}{r}\text { Teste } \\
\text { de Auto- } \\
\text { correlação }\end{array}$ & $\begin{array}{r}\text { Forma } \\
\text { Funcional }\end{array}$ & $\begin{array}{r}\text { Norma- } \\
\text { lidade }\end{array}$ & $\begin{array}{r}\text { Hetero- } \\
\text { cedasti- } \\
\text { cidade }\end{array}$ & AKAIKE \\
\hline \multirow[t]{5}{*}{$\frac{\pi}{4}$} & $\begin{array}{r}\text { Aeronáutica e } \\
\text { Aeroespacial }(2,1,2,0) \\
\end{array}$ & $\begin{array}{r}4,2049 \\
{[0,040]}\end{array}$ & $\begin{array}{l}2,2226 \\
{[0,136]}\end{array}$ & $\begin{array}{r}0,69487 \\
{[0,706]} \\
\end{array}$ & $\begin{array}{l}1,0298 \\
{[0,310]}\end{array}$ & 18,8188 \\
\hline & $\begin{array}{r}\text { Equipamentos de Rádio, } \\
\text { TV e Comunicação } \\
(1,0,1,1)\end{array}$ & $\begin{array}{r}0,002877 \\
{[0,957]}\end{array}$ & $\begin{array}{r}8,0234 \\
{[0,005]}\end{array}$ & $\begin{array}{l}0,83175 \\
{[0,660]}\end{array}$ & $\begin{array}{r}4,1714 \\
{[0,041]}\end{array}$ & $-1,5422$ \\
\hline & $\begin{array}{r}\text { Farmacêutica } \\
\qquad(0,1,1,1)\end{array}$ & $\begin{array}{r}0,7577 \\
{[0,978]}\end{array}$ & $\begin{array}{l}11,6507 \\
{[0,001]}\end{array}$ & $\begin{array}{r}0,96494 \\
{[0,617]}\end{array}$ & $\begin{array}{r}5,4501 \\
{[0,020]}\end{array}$ & $-7,3701$ \\
\hline & $\begin{array}{r}\text { Instrumentos Médicos } \\
\text { de Ótica e Pressão } \\
(2,0,2,1)\end{array}$ & $\begin{array}{l}0,11715 \\
{[0,732]}\end{array}$ & $\begin{array}{l}13,4215 \\
{[0,000]}\end{array}$ & $\begin{array}{r}0,67482 \\
{[0,714]}\end{array}$ & $\begin{array}{r}0,4015 \\
{[0,526]}\end{array}$ & $-8,8026$ \\
\hline & $\begin{array}{l}\text { Material de Escritório e } \\
\text { Informática }(1,2,2,2)\end{array}$ & $\begin{array}{r}1,1072 \\
{[0,293]}\end{array}$ & $\begin{array}{l}10,3019 \\
{[0,001]}\end{array}$ & $\begin{array}{l}0,71395 \\
{[0,700]}\end{array}$ & $\begin{array}{r}0,020812 \\
{[0,885]}\end{array}$ & $-13,6493$ \\
\hline
\end{tabular}

serão captados pela metodologia. Portanto, a periodicidade dos dados pode limitar resultados favoráveis à Curva J.

5 Os setores de alta tecnologia são Aeronáutica e Aeroespacial; Equipamentos de Rádio, TV e Comunicação; Farmacêutica; Instrumentos Médicos de Ótica e Pressão; Material de Escritório e Informática. De média-alta tecnologia, compreendem Equipamentos para Ferrovia e Material de Transporte N. E.; Máquinas e Equipamentos Elétricos N. E.; Máquinas e Equipamentos Mecânicos N. E.; Produtos Químicos, Excl. Farmacêuticos; e Veículos Automotores, Reboques e Semirreboques. De média-baixa tecnologia: Borracha e Produtos Plásticos; Construção e Reparação Naval; Outros Produtos Minerais Não Metálicos; Produtos de Petróleo Refinado e Outros Combustíveis; e Produtos Metálicos. De baixa tecnologia: Alimentos, Bebidas e Tabaco; Madeira e seus Produtos, Papel e Celulose; Produtos Manufaturados N. E. e Bens Reciclados; e Têxteis, Couro e Calçados.

6 Critério de Informação de Akaike usado para a seleção do modelo probabilisticamente melhor. 


\begin{tabular}{|c|c|c|c|c|c|c|}
\hline \begin{tabular}{l|}
$\frac{\pi}{80}$ \\
$\frac{0}{0}$ \\
$\frac{0}{0}$ \\
\end{tabular} & $\begin{array}{r}\text { Setor/ } \\
\text { Modelo ARDL }\end{array}$ & $\begin{array}{r}\text { Teste } \\
\text { de Auto- } \\
\text { correlação }\end{array}$ & $\begin{array}{r}\text { Forma } \\
\text { Funcional }\end{array}$ & $\begin{array}{r}\text { Norma- } \\
\text { lidade }\end{array}$ & $\begin{array}{r}\text { Hetero- } \\
\text { cedasti- } \\
\text { cidade }\end{array}$ & AKAIKE \\
\hline \multirow[t]{5}{*}{$\begin{array}{l}\frac{\pi}{\pi} \\
\frac{\pi}{\pi} \\
\frac{\pi}{0} \\
\frac{\pi}{20} \\
\sum\end{array}$} & $\begin{array}{r}\text { Equipamentos para } \\
\text { Ferrovia e Material de } \\
\text { Transporte N. E. }(1,0,1,1)\end{array}$ & $\begin{array}{r}0,29403 \\
{[0,588]}\end{array}$ & $\begin{array}{r}0,26012 \\
{[0,610]}\end{array}$ & $\begin{array}{r}1,8398 \\
{[0,399]}\end{array}$ & $\begin{array}{l}1,2622 \\
{[0,261]}\end{array}$ & $-13,3072$ \\
\hline & $\begin{array}{r}\text { Máquinas e Equipa- } \\
\text { mentos Elétricos N. E. } \\
(1,1,1,1)\end{array}$ & $\begin{array}{r}3,7724 \\
{[0,052]}\end{array}$ & $\begin{array}{l}4,9996 \\
{[0,025]}\end{array}$ & $\begin{array}{r}2,4534 \\
{[0,293]}\end{array}$ & $\begin{array}{r}0,67536 \\
{[0,411]}\end{array}$ & 4,6138 \\
\hline & $\begin{array}{r}\text { Máquinas e Equipa- } \\
\text { mentos Mecânicos N. E. } \\
(0,0,0,0) \\
\text { apenas para } 1 \mathrm{ARDL}\end{array}$ & $\begin{array}{l}0,0098 \\
{[0,921]}\end{array}$ & $\begin{array}{r}2,6125 \\
{[0,106]}\end{array}$ & $\begin{array}{r}105,7595 \\
{[0,000]}\end{array}$ & $\begin{array}{r}1,3868 \\
{[0,239]}\end{array}$ & $-39,5076$ \\
\hline & $\begin{array}{l}\text { Produtos Químicos, Excl. } \\
\text { Farmacêuticos }(2,2,0,2)\end{array}$ & $\begin{array}{r}5,4755 \\
{[0,005]}\end{array}$ & $\begin{array}{r}0,54356 \\
{[0,461]}\end{array}$ & $\begin{array}{r}0,3951 \\
{[0,821]}\end{array}$ & $\begin{array}{r}0,3265 \\
{[0,568]}\end{array}$ & 8,5418 \\
\hline & $\begin{array}{r}\text { Veículos Automotores, } \\
\text { Reboques e Semirrebo- } \\
\text { ques }(2,0,2,0)\end{array}$ & $\begin{array}{r}2,7565 \\
{[0,097]}\end{array}$ & $\begin{array}{r}0,55076 \\
{[0,458]}\end{array}$ & $\begin{array}{r}0,18619 \\
{[0,911]}\end{array}$ & $\begin{array}{r}1,1329 \\
{[0,287]}\end{array}$ & $-13,0744$ \\
\hline \multirow{5}{*}{ 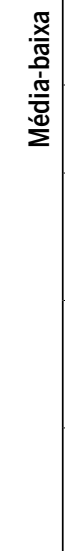 } & $\begin{array}{r}\text { Borracha e Produtos } \\
\text { Plásticos }(1,1,0,0)\end{array}$ & $\begin{array}{r}0,57066 \\
{[0,450]}\end{array}$ & $\begin{array}{r}0,59424 \\
{[0,441]}\end{array}$ & $\begin{array}{r}0,42764 \\
{[0,807]}\end{array}$ & $\begin{array}{l}0,81731 \\
{[0,366]}\end{array}$ & 14,8179 \\
\hline & $\begin{array}{r}\text { Construção e Reparação } \\
\text { Naval }(2,1,2,2)\end{array}$ & $\begin{array}{r}1,5416 \\
{[0,214]}\end{array}$ & $\begin{array}{r}8,673 \\
{[0,03]}\end{array}$ & $\begin{array}{r}0,35924 \\
{[0,836]}\end{array}$ & $\begin{array}{r}0,0001337 \\
{[0,991]}\end{array}$ & $-22,671$ \\
\hline & $\begin{array}{r}\text { Outros Produtos } \\
\text { Minerais Não Metálicos } \\
(1,0,2,0)\end{array}$ & $\begin{array}{r}0,037989 \\
{[0,845]}\end{array}$ & $\begin{array}{r}2,7591 \\
{[0,097]}\end{array}$ & $\begin{array}{r}0,71023 \\
{[0,701]}\end{array}$ & $\begin{array}{r}1,9611 \\
{[0,161]}\end{array}$ & 9,3614 \\
\hline & $\begin{array}{r}\text { Produtos de Petróleo } \\
\text { Refinado e Outros Com- } \\
\text { bustíveis }(0,2,2,2)\end{array}$ & $\begin{array}{l}2,5134 \\
{[0,113]}\end{array}$ & $\begin{array}{l}2,4623 \\
{[0,117]}\end{array}$ & $\begin{array}{r}3,7234 \\
{[0,155]}\end{array}$ & $\begin{array}{r}0,78082 \\
{[0,377]}\end{array}$ & $-3,9861$ \\
\hline & $\begin{array}{r}\text { Produtos Metálicos } \\
\qquad(1,0,1,1) \\
\text { apenas para 1 ARDL }\end{array}$ & $\begin{array}{r}0,7823 \\
{[0,376]}\end{array}$ & $\begin{array}{r}0,49715 \\
{[0,481]}\end{array}$ & $\begin{array}{l}2,8346 \\
{[0,242]}\end{array}$ & $\begin{array}{l}0,01891 \\
{[0,891]}\end{array}$ & 6,9645 \\
\hline \multirow[t]{4}{*}{ 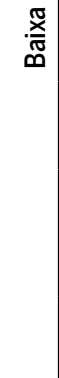 } & $\begin{array}{r}\text { Alimentos, Bebidas } \\
\text { e Tabaco }(1,2,2,2)\end{array}$ & $\begin{array}{r}0,32389 \\
{[0,569]} \\
\end{array}$ & $\begin{array}{r}7,3592 \\
{[0,007]} \\
\end{array}$ & $\begin{array}{l}3,1045 \\
{[0,212]} \\
\end{array}$ & $\begin{array}{r}1,1624 \\
{[0,281]}\end{array}$ & $-10,4244$ \\
\hline & $\begin{array}{r}\text { Madeira e seus Produtos, } \\
\text { Papel e Celulose }(1,1,1,2)\end{array}$ & $\begin{array}{r}0,69393 \\
{[0,405]}\end{array}$ & $\begin{array}{r}0,037231 \\
{[0,847]}\end{array}$ & $\begin{array}{l}2,5593 \\
{[0,278]}\end{array}$ & $\begin{array}{l}1,6462 \\
{[0,199]}\end{array}$ & 13,1793 \\
\hline & $\begin{array}{r}\text { Produtos Manufaturados } \\
\text { N. E. e Bens Reciclados } \\
(2,2,2,1)\end{array}$ & $\begin{array}{r}0,96486 \\
{[0,326]}\end{array}$ & $\begin{array}{r}0,4899 \\
{[0,484]}\end{array}$ & $\begin{array}{r}1,012 \\
{[0,603]}\end{array}$ & $\begin{array}{l}2,0025 \\
{[0,157]}\end{array}$ & 21,3342 \\
\hline & $\begin{array}{r}\text { Têxteis, Couro e } \\
\text { Calçados }(2,2,1,0)\end{array}$ & $\begin{array}{r}0,25418 \\
{[0,614]}\end{array}$ & $\begin{array}{r}0,25135 \\
{[0,616]}\end{array}$ & $\begin{array}{l}16,8445 \\
{[0,000]}\end{array}$ & $\begin{array}{l}1,8775 \\
{[0,171]}\end{array}$ & 20,7231 \\
\hline
\end{tabular}

Fonte: Elaboração própria com base emdados da SECEX/MDIC.

Nota: Os valores entre colchetes se referem à estatística $F$. 
O teste de autocorrelação indica não rejeição da hipótese nula, ou seja, a ausência de autocorrelação entre os resíduos para os setores de Aeronáutica e Aeroespacial; Equipamentos de Rádio, TV e Comunicação; Farmacêutica; Instrumentos Médicos de Ótica e Pressão; Material de Escritório e Informática; Equipamentos para Ferrovia e Material de Transporte N.E.; Máquinas e Equipamentos Elétricos N. E.; Máquinas e Equipamentos Mecânicos N.E.; Veículos Automotores, Reboques e Semirreboques; Borracha e Produtos Plásticos; Construção e Reparação Naval; Outros Produtos Minerais Não Metálicos; Produtos de Petróleo Refinado e Outros Combustíveis; Produtos Metálicos; Alimentos, Bebidas e Tabaco; Madeira e seus Produtos, Papel e Celulose; Produtos Manufaturados N. E. e Bens Reciclados; Têxteis, Couro e Calçados, ao nível de significância de 1\%.

Em relação à forma funcional, teste RESET,7 a hipótese nula não é rejeitada para os setores de Aeronáutica e Aeroespacial; Equipamentos para Ferrovia e Material de Transporte N. E.; Máquinas e Equipamentos Elétricos N.E.; Máquinas e Equipamentos Mecânicos N. E.; Produtos Químicos, Excl. Farmacêuticos; Veículos Automotores, Reboques e Semirreboques; Borracha e Produtos Plásticos; Outros Produtos Minerais Não Metálicos; Produtos de Petróleo Refinado e Outros Combustíveis; Produtos Metálicos; Madeira e seus Produtos, Papel e Celulose; Produtos Manufaturados N. E. e Bens Reciclados; Têxteis, Couro e Calçados, isto é, para esses setores, o teste indica uma forma funcional adequada.

Observando os resultados do teste de normalidade Jarque-Bera, ${ }^{8}$ é possível verificar que os setores de Aeronáutica e Aeroespacial; Equipamentos de Rádio, TV e Comunicação; Farmacêutica;Instrumentos Médicos de Ótica e Pressão; Material de Escritório e Informática; Equipamentos para Ferrovia e Material de Transporte N. E.; Máquinas e Equipamentos Elétricos N. E.; Produtos Químicos, Excl. Farmacêuticos; Veículos Automotores, Reboques e Semirreboques; Borracha e Produtos Plásticos; Construção e Reparação Naval; Outros Produtos Minerais Não Metálicos; Produtos de Petróleo Refinado e Outros Combustíveis; Produtos Metálicos; Alimentos,

\footnotetext{
7 O Teste RESET de Ramsey é o mais empregado para verificar erros de especificações em modelos que pode, ocorrer por omissão de variável relevante, inclusão de variável irrelevante, adoção de forma funcional errada ou erros de medida (Wooldridge, 2010).

8 O teste de normalidade Jarque-Bera é utilizado para determinar se os dados de uma dada variável aleatória são modelados por uma distribuição normal ou não.
} 
Bebidas e Tabaco; Madeira e seus Produtos, Papel e Celulose; Produtos Manufaturados N. E. e Bens Reciclados indicam pela não rejeição da hipótese de normalidade. Logo, nos demais estatisticamente significativos, a hipótese de normalidade não pode ser rejeitada.

Em relação ao teste de heteroscedasticidade de White, ${ }^{9}$ não foram encontradas evidências desse problema, tendo em vista que, em nenhum dos modelos ARDL setoriais, a hipótese nula de homocedasticidade não pode ser rejeitada, ou seja, todos apresentam resíduos homocedásticos.

Em resumo, os testes de diagnósticos sugerem que os modelos ARDL para os setores de Aeronáutica e Aeroespacial; Equipamentos para Ferrovia e Material de Transporte N. E.; Veículos Automotores, Reboques e Semirreboques; Borracha e Produtos Plásticos; Construção e Reparação Naval; Outros Produtos Minerais Não Metálicos; Produtos de Petróleo Refinado e Outros Combustíveis; Produtos Metálicos; Madeira e seus Produtos, Papel e Celulose; Produtos Manufaturados N. E. e Bens Reciclados possuem especificação adequada.

Em seguida, foram aplicados testes de cointegração de Pesaran et al. (2001) apenas nos setores com modelos ARDL bem especificados, cujos resultados estão apresentados na Tabela 2 . $O$ teste permite identificara existência ou não de uma relação de longo prazo.

Tabela 2 Teste de Cointegração - Setores Industriais, 1996 - 2012

\begin{tabular}{|c|c|c|c|c|c|c|}
\hline \multirow{2}{*}{$\begin{array}{l}\frac{\pi}{00} \\
\frac{.0}{0} \\
\frac{0}{0} \\
\end{array}$} & \multirow{2}{*}{$\begin{array}{r}\text { Setor/ } \\
\text { Modelo ARDL }\end{array}$} & \multicolumn{2}{|c|}{ Valores Críticos 95\% } & \multicolumn{2}{|c|}{ Valores Encontrados } & \multirow[b]{2}{*}{ Decisão } \\
\hline & & $\begin{array}{r}\text { Estatística } \\
\mathbf{F}\end{array}$ & $\begin{array}{r}\text { Estatística } \\
\mathrm{W}\end{array}$ & $\begin{array}{r}\text { Estatística } \\
\mathbf{F}\end{array}$ & $\begin{array}{r}\text { Estatística } \\
\text { W }\end{array}$ & \\
\hline$\frac{\pi}{2}$ & $\begin{array}{r}\text { Aeronáutica e } \\
\text { Aeroespacial }(2,1,2,0)\end{array}$ & 4,856 & 19,4238 & 7,42 & 29,68 & Cointegração \\
\hline \multirow[t]{3}{*}{$\begin{array}{l}\frac{\pi}{\pi} \\
\frac{\pi}{\pi} \\
\frac{i}{\pi} \\
\frac{\pi}{0} \\
\sum\end{array}$} & $\begin{array}{r}\text { Equipamentos para } \\
\text { Ferrovia e Material de } \\
\text { Transporte N. E. }(1,0,1,1)\end{array}$ & 4,856 & 19,4238 & 3,168 & 12,672 & $\begin{array}{r}\text { Não há } \\
\text { Cointegração }\end{array}$ \\
\hline & $\begin{array}{r}\text { Máquinas e Equipa- } \\
\text { mentos Elétricos } \mathrm{N} . \mathrm{E} . \\
(1,1,1,1)\end{array}$ & 4,856 & 19,4238 & 0,5857 & 2,3428 & $\begin{array}{r}\text { Não há } \\
\text { Cointegração }\end{array}$ \\
\hline & $\begin{array}{r}\text { Veículos Automotores, } \\
\text { Reboques e Semirre- } \\
\text { boques }(2,0,2,0)\end{array}$ & 4,856 & 19,4238 & 3,6715 & 14,686 & $\begin{array}{r}\text { Não há } \\
\text { Cointegração }\end{array}$ \\
\hline
\end{tabular}

9 O teste de White é utilizado para identificar se há relação linear entre os resíduos. 


\begin{tabular}{|c|c|c|c|c|c|c|}
\hline \multirow{2}{*}{$\begin{array}{l}\frac{\pi}{80} \\
\frac{0}{0} \\
\frac{0}{0} \\
\stackrel{0}{0}\end{array}$} & \multirow{2}{*}{$\begin{array}{r}\text { Setor/ } \\
\text { Modelo ARDL }\end{array}$} & \multicolumn{2}{|c|}{ Valores Críticos $95 \%$} & \multicolumn{2}{|c|}{ Valores Encontrados } & \multirow[b]{2}{*}{ Decisão } \\
\hline & & $\begin{array}{r}\text { Estatística } \\
\mathbf{F}\end{array}$ & $\begin{array}{r}\text { Estatística } \\
\mathrm{W}\end{array}$ & $\begin{array}{r}\text { Estatística } \\
\mathbf{F}\end{array}$ & $\begin{array}{r}\text { Estatística } \\
\mathrm{W}\end{array}$ & \\
\hline \multirow{5}{*}{ 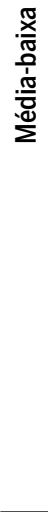 } & $\begin{array}{r}\text { Borracha e Produtos } \\
\text { Plásticos }(1,1,0,0)\end{array}$ & 4,856 & 19,4238 & 2,3673 & 9,4602 & $\begin{array}{r}\text { Não há } \\
\text { Cointegração }\end{array}$ \\
\hline & $\begin{array}{r}\text { Construção e Reparação } \\
\text { Naval }(2,1,2,2)\end{array}$ & 4,856 & 19,4238 & 13,256 & 53,0241 & Cointegração \\
\hline & $\begin{array}{r}\text { Outros Produtos } \\
\text { Minerais Não-Metálicos } \\
(1,0,2,0)\end{array}$ & 4,856 & 19,4238 & 5,5437 & 22,1746 & Cointegração \\
\hline & $\begin{array}{r}\text { Produtos de Petróleo } \\
\text { Refinado e Outros Com- } \\
\text { bustíveis }(0,2,2,2)\end{array}$ & - & - & - & - & - \\
\hline & $\begin{array}{r}\text { Produtos Metálicos } \\
\qquad(1,0,1,1)\end{array}$ & 4,856 & 19,4238 & 3,498 & 13,9921 & $\begin{array}{r}\text { Não há } \\
\text { Cointegração }\end{array}$ \\
\hline \multirow[t]{2}{*}{$\underset{\mathscr{x}}{\stackrel{\widetilde{x}}{\mathbb{N}}}$} & $\begin{array}{r}\text { Madeira e seus Produtos, } \\
\text { Papel e Celulose }(1,1,1,2)\end{array}$ & 4,856 & 19,4238 & 8,6955 & 34,7819 & Cointegração \\
\hline & $\begin{array}{r}\text { Produtos Manufaturados } \\
\text { N. E. e Bens Reciclados } \\
(2,2,2,1)\end{array}$ & 4,856 & 19,4238 & 9,7787 & 39,1148 & Cointegração \\
\hline
\end{tabular}

Fonte: Elaboração própria com base em dados da SECEX/MDIC.

De acordo com a Tabela 2, o teste de cointegração indicou evidência favorável a uma relação de equilíbrio no longo prazo - entre as variáveis PIB Brasil, PIB Mundial, taxa de câmbio real e saldo da balança comercial - nos setores de Aeronáutica e Aeroespacial; Construção e Reparação Naval; Outros Produtos Minerais Não Metálicos; Produtos Manufaturados N. E. e Bens Reciclados; Madeira e seus Produtos, Papel e Celulose. Com isso, têm-se cinco setores com possibilidade de um fenômeno da Curva J completa.Portanto, serão analisados apenas os resultados desses cinco setores(Tabela 3). Em relação ao setor Produtos de Petróleo Refinado e Outros Combustíveis, infelizmente, não foi possível aplicar o teste de cointegração, dada a limitação dos dados.

$\mathrm{Na}$ Tabela 3, estão expostos os resultados do modelo ARDL de curto prazo. Foram encontrados valores negativos e estatisticamente significativos para $\mathrm{O}$ coeficiente da variável PIB do Brasil nos setores de Madeira e seus Produtos, Papel e Celulose e Produtos Manufaturados N. E. e Bens Reciclados. Por sua vez, o coeficiente da variável PIB Mundial apresentou valores positivos para os cinco setores. Esses resultados estão alinhados à teoria econômica. 


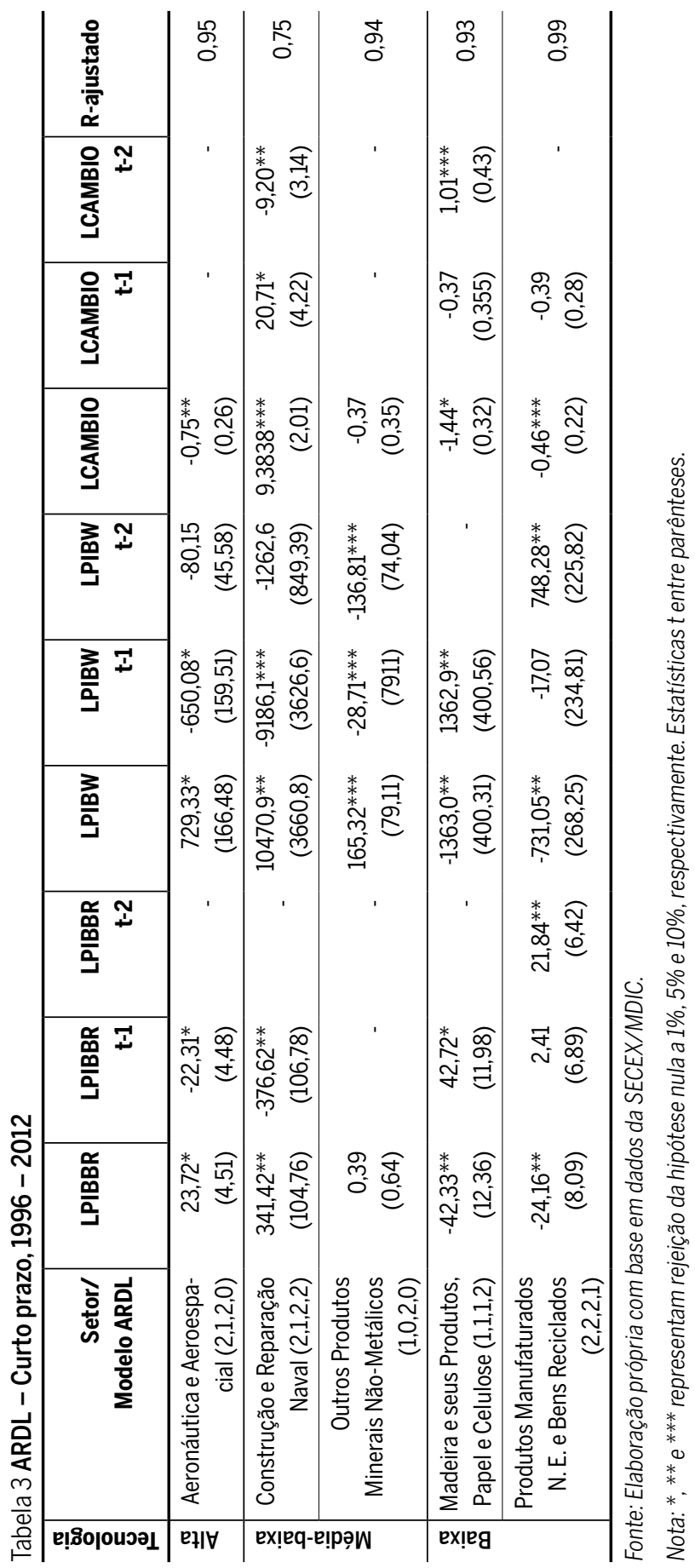


O coeficiente da variável Câmbio exibiu valores negativos e significativos para os setores de Aeronáutica e Aeroespacial; Madeira e seus Produtos, Papel e Celulose; e Produtos Manufaturados N. E. e Bens Reciclados. De acordo com Rose e Yellen (1989), espera-se que o coeficiente do câmbio seja negativo para confirmar, embora ainda de maneira incompleta, a Curva J. Assim, há evidências favoráveis da fase inicial da Curva J para os referidos setores.

Especificamente para o setor de Construção e Reparação Naval, o valor da elasticidade do câmbio de curto prazo indica características do efeito Curva J incompleto, porém de maneira invertida, ou seja, uma redução da taxa de câmbio (apreciação cambial) resulta em aumento do saldo da balança comercial. Considerando que os resultados de curto prazo sugerem uma Curva J incompleta, a confirmação do efeito Curva J por completo está condicionada a um sinal positivo do coeficiente da variável Câmbio na análise de longo prazo.

$\mathrm{Na}$ Tabela 4, estão expostas estimativas dos modelos ARDL de longo prazo para os mesmos setores. Em nenhum dos cinco setores analisados, as evidências sugerem que o referido fenômeno seja completo, isto é, que a depreciação da taxa de câmbio real provoque deterioração no saldo do $\mathrm{BC}$ no curto prazo com resposta positiva no longo prazo, conforme estabelecido pela teoria da Curva J.A exceção foi o setor de Construção e Reparação Naval, cujo coeficiente positivo e estatisticamente significativo da variável Câmbio, poderia indicar uma possível Curva J.

Tabela 4 ARDL - Longo prazo, 1996 - 2012

\begin{tabular}{|c|c|c|c|c|c|}
\hline $\begin{array}{l}\frac{\pi}{80} \\
\frac{0}{0} \\
\frac{}{0} \\
\mathbb{0}\end{array}$ & Setor/Modelo ARDL & LnPIBBR & LnPIBW & LnCAMBIO & Curva J \\
\hline$\frac{\pi}{4}$ & $\begin{array}{r}\text { Aeronáutica e } \\
\text { Aeroespacial }(2,1,2,0)\end{array}$ & $\begin{array}{r}2,57^{*} \\
(0,63)\end{array}$ & $\begin{array}{l}-1,65^{*} \\
(0,43)\end{array}$ & $\begin{array}{l}-1,37^{*} \\
(0,37)\end{array}$ & $\begin{array}{l}\text { Não há } \\
\text { indicação }\end{array}$ \\
\hline $\begin{array}{c}\frac{\pi}{\pi} \\
\frac{\pi}{\tilde{T}} \\
\frac{1}{1}\end{array}$ & $\begin{array}{r}\text { Construção e Reparação Naval } \\
\qquad(2,1,2,2)\end{array}$ & $\begin{array}{r}-22,63^{*} \\
(3,98)\end{array}$ & $\begin{array}{l}14,30^{*} \\
(2,60)\end{array}$ & $\begin{array}{l}13,43^{*} \\
(2,38)\end{array}$ & $\begin{array}{r}\text { Não há } \\
\text { indicação }\end{array}$ \\
\hline 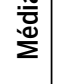 & $\begin{array}{r}\text { Outros Produtos Minerais Não- } \\
\text {-Metálicos }(1,0,2,0)\end{array}$ & $\begin{array}{r}-4,81 \\
(9,84)\end{array}$ & $\begin{array}{r}2,50 \\
(5,76)\end{array}$ & $\begin{array}{r}4,50 \\
(8,81)\end{array}$ & $\begin{array}{l}\text { Não há } \\
\text { indicação }\end{array}$ \\
\hline $\begin{array}{c}\stackrel{\widetilde{x}}{\tilde{\mathbb{N}}} \\
\ddot{\infty}\end{array}$ & $\begin{array}{r}\text { Madeira e seus Produtos, Papel e } \\
\text { Celulose }(1,1,1,2)\end{array}$ & $\begin{array}{r}-1,09 \\
(3,15)\end{array}$ & $\begin{array}{r}0,30 \\
(1,83)\end{array}$ & $\begin{array}{r}2,22 \\
(2,49)\end{array}$ & $\begin{array}{r}\text { Não há } \\
\text { indicação }\end{array}$ \\
\hline & $\begin{array}{r}\text { Produtos Manufaturados N. E. e } \\
\text { Bens Reciclados }(2,2,2,1)\end{array}$ & $\begin{array}{r}4,60 \\
(16,17)\end{array}$ & $\begin{array}{r}7,01 \\
(35,83)\end{array}$ & $\begin{array}{r}-38,53 \\
(134,03)\end{array}$ & $\begin{array}{r}\text { Não há } \\
\text { indicação }\end{array}$ \\
\hline
\end{tabular}

Fonte: Elaboração própria, com base em dados do SECEX/MDIC.

Nota: ${ }^{*},{ }^{* *} e^{* * *}$ representam rejeição da hipótese nula a $1 \%, 5 \%$ e $10 \%$, respectivamente. 
Todavia, ao se observar os resultados da Tabela 3, constata-se que esse setor não possui o sinal de coeficiente do câmbio que favoreça a hipótese do efeito Curva J de forma convencional, mas de forma invertida. Isto é, o saldo comercial desse setor responde positivamente às mudanças na taxa de câmbio real tanto no curto quanto no longo prazo.

De maneira geral, não foi possível encontrar indicação do fenômeno Curva J completo para nenhum dos setores quando confrontados os resultados de curto e longo prazos, mesmo realizando uma análise desagregada, conforme sugeriram Mendes e Pisa (2007) e Moura e Silva (2005). Entretanto, foram constatadas apenas evidências empíricas de um fenômeno incompleto, já que foram encontrados valores de elasticidades do saldo da balança comercial em relação ao câmbio negativas no curto prazo (Tabela 3). Exclusivamente quanto ao setor de Construção e Reparação Naval, os valores de elasticidades do saldo com o câmbio são positivos no curto prazo, indicando características do fenômeno da Curva J de forma invertida. Esses resultados podem ter sido influenciados pelo tamanho do período analisado (1996-2012).

Por fim, em relação ao coeficiente do PIB do Brasil e do PIB Mundial, apenas o setor de Construção e Reparação Naval apresentou o sinal negativo e positivo, respectivamente, corroborando a teoria econômica.

Concluídas as observações em curto e longo prazos, na Tabela 5 estão apresentados os resultados do modelo completo, acrescentando o mecanismo de correção de erros, definida pelo termo ecm (-1), em inglês Error Correction Mechanism (ECM). O ecm (-1) mede a velocidade dos ajustes em curto prazo provocados pelo choque (taxa de câmbio) na variável de interesse (saldo da balança comercial), a restabelecer o equilíbrio em longo prazo.

Tabela 5 ARDL - Completo, 1996 - 2012

\begin{tabular}{|c|c|c|c|c|c|}
\hline $\begin{array}{l}\frac{\pi}{00} \\
\text { 응 } \\
\frac{0}{0} \\
\stackrel{0}{0}\end{array}$ & Setor/Modelo ARDL & dLnCAMBIO & $\begin{array}{r}\text { dLnCAMBIO } \\
\mathrm{t}-1\end{array}$ & $\begin{array}{r}\mathrm{ECM} \\
(-1)\end{array}$ & AKAIKE \\
\hline$\frac{\pi}{\frac{\pi}{\alpha}}$ & $\begin{array}{r}\text { Aeronáutica e } \\
\text { Aeroespacial }(2,1,2,0)\end{array}$ & $\begin{array}{l}-0,75^{*} \\
(0,26)\end{array}$ & - & $\begin{array}{r}-0,55^{* * *} \\
(0,08)\end{array}$ & 18,82 \\
\hline \multirow{2}{*}{ 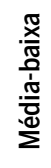 } & $\begin{array}{r}\text { Construção e Reparação Naval } \\
(2,1,2,2)\end{array}$ & $\begin{array}{r}9,38 * * * \\
(4,66) \\
\end{array}$ & $\begin{array}{r}9,20 * * \\
(3,14)\end{array}$ & $\begin{array}{r}-1,55^{* * *} \\
(0,24) \\
\end{array}$ & $-22,67$ \\
\hline & $\begin{array}{r}\text { Outros Produtos Minerais } \\
\text { Não-Metálicos }(1,0,2,0)\end{array}$ & $\begin{array}{r}-0,37 \\
(0,36)\end{array}$ & & $\begin{array}{r}0,08 \\
(0,12)\end{array}$ & 9,36 \\
\hline
\end{tabular}




\begin{tabular}{|c|c|c|c|c|c|}
\hline 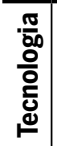 & Setor/Modelo ARDL & dLnCAMBIO & $\begin{array}{r}\text { dLnCAMBIO } \\
\text { t-1 }\end{array}$ & $\begin{array}{r}\text { ECM } \\
(-1)\end{array}$ & AKAIKE \\
\hline \multirow[t]{2}{*}{$\frac{\mathbb{x}}{\sqrt[x]{\mathbb{N}}}$} & $\begin{array}{l}\text { Madeira e seus Produtos, } \\
\text { Papel e Celulose }(1,1,1,2)\end{array}$ & $\begin{array}{l}-1,44^{*} \\
(0,32)\end{array}$ & $\begin{array}{l}-1,01^{* *} \\
(0,43)\end{array}$ & $\begin{array}{r}-0,14^{* *} \\
(0,11)\end{array}$ & 13,18 \\
\hline & $\begin{array}{r}\text { Produtos Manufaturados N. E. } \\
\text { e Bens Reciclados }(2,2,2,1)\end{array}$ & $\begin{array}{r}-0,46^{* * *} \\
(0,22)\end{array}$ & & $\begin{array}{r}-0,022^{* * *} \\
(0,0061)\end{array}$ & 21,33 \\
\hline
\end{tabular}

Fonte: Elaboração própria, com base em dados do SECEX/MDIC.

Nota: ${ }^{*},{ }^{* *} e^{* * *}$ representam rejeição da hipótese nula a 1\%, 5\% e 10\%, respectivamente.

O modelo de correção de erro está exposto na Tabela 5. Todos os termos ECM(t-1) são negativos e significativos, exceto para o setor Outros Produtos Minerais Não Metálicos. ECM mede a velocidade na qual o saldo comercial se ajusta às mudanças nas variáveis explicativas (PIB Mundial, PIB Brasil e taxa de câmbio real). Por exemplo, no setor Aeronáutica e Aeroespacial, o coeficiente de $-0,54$ indica que $54 \%$ do desvio entre o saldo comercial atual e o saldo comercial de equilíbrio é incorporado (corrigido) a cada período (ano). Portanto, tais resultados sugerem que desvios no equilíbrio de longo prazo convergem ao estado estacionário, ou seja, que o saldo comercial da maioria dos setores analisados ajusta-se ao equilíbrio dadas alterações na Taxa de Câmbio Real, PIB Mundial ou PIB Brasil.

\section{Considerações finais}

Este artigo buscou analisar a relação de curto e longo prazos entre a taxa de câmbio real e o saldo comercial de 19 setores industriais do Brasil em relação ao Resto do Mundo, na tentativa de testar o efeito Curva J, de acordo com o modelo proposto por Rose e Yellen (1989), no qual o saldo comercial é explicado pela taxa de câmbio real, pela renda doméstica e pela renda externa. Segundo Frankel, Caves e Jones (2001), se a condição Marshall-Lerner é satisfeita, uma depreciação da taxa de câmbio implicaria uma melhora no saldo da balança comercial. Contudo, essa resposta seria positiva apenas no longo prazo, uma vez que o saldo comercial responderia negativamente às mudanças na taxa de câmbio no curto prazo, formando uma Curva J. Isto é, espera-se que a elasticidade do saldo em relação àtaxa de câmbio seja negativa no curto prazo e positiva no longo prazo. 
Utilizando dados anuais da UNCOMTRADE que correspondem ao período de 1996 a 2012, a Curva J foi estimada usando o método ARDL com cointegração proposto por Pesaran et al. (2001). Essa abordagem permite captar simultaneamente as dinâmicas de curto e longo prazos das variáveis analisadas. A literatura empírica internacional sugere tal abordagem ao estudo do referido fenômeno (Bahmani-Oskooee; Harvey, 2006; Bahmani-Oskooee; Kutan, 2009).

Os resultados dos testes de cointegração ${ }^{1}$ identificaram que, dos 19 setores industriais, apenas cinco apresentam relação de longo prazo entre as variáveis taxa de câmbio real, PIB Brasil e PIB Mundial. Desse modo, as referidas variáveis explicam as mudanças no saldo da balança comercial no longo prazo. Assim, as dinâmicas de curto e longo prazos dos saldos comerciais dos cinco setores foram analisadas em busca de alguma evidência da Curva J.

No tocante ao curto prazo, os resultados encontrados apontam que quatro setores apresentam valores de elasticidades negativos do saldo da balança comercial em relação ao câmbio e apenas um exibiu elasticidade positiva. Há indicação da fase inicial da Curva J, nos setores Aeronáutica e Aeroespacial; Madeira e seus Produtos, Papel e Celulose; e Produtos Manufaturados N. E. e Bens Reciclados. Nesses setores, a depreciação cambial resultaria em deterioração no saldo da balança comercial. Em contraposição, está o setor Construção e Reparação Naval, cuja elasticidade positiva do saldo em relação àtaxa de câmbio sugere que a depreciação cambial provoca melhoras no saldo da balança comercial já no curto prazo. Isso indica que o setor pode exibir uma forma invertida do efeito Curva J.

Em relação ao longo prazo, não foram encontradas evidências de elasticidades positivas (coeficientes positivos) do saldo em relação à taxa de câmbio para nenhum dos setores analisados. Assim, não há indicação do fenômeno Curva J completo para nenhum dos cinco setores analisados quando confrontados os resultados de curto e longo prazos, mesmo realizando uma análise desagregada, conforme sugeriram Mendes e Pisa (2007) e Moura e Silva (2005). Entretanto, foram constatadas apenas evidências empíricas de um fenômeno incompleto, visto que se encontraram elasticidades negativas do saldo da balança comercial em relação ao câmbio no curto prazo (Tabela 3). Resultados similares foram obtidos por Sonaglio, Scalco e Campos (2010).

1 Os testes de diagnósticos sugerem que os modelos ARDL estimados estão bem especificados. 
Portanto, os resultados sugerem que as mudanças na taxa de câmbio influenciam negativamente o saldo da balança comercial brasileira no curto prazo independentemente do nível tecnológico das indústrias. Infere-se, dessa forma, a necessidade de definir uma política cambial e comercial capaz de preservar/estimular a competitividade dos setores exportadores brasileiros que não dependa de possíveis efeitos cambiais de longo prazo.

Vale destacar que a limitação dos dados obtidos (apenas 16 anos foram analisados) e o período analisado de mudança no regime cambial brasileiro podem prejudicar a identificação da Curva J completa. Ainda assim, mesmo diante dessas limitações, os resultados apresentaram potenciais evidências do fenômeno Curva J, muito embora de maneira incompleta.

\section{Referências}

BAHMANI-OSKOOEE, M.; ARDALANI, Z. Is there a J-curve at the industry level. Economics Bulletin, v. 6, n. 26, p. 1-12, 2007.

BAHMANI-OSKOOEE, M.; HARVEY, H. How sensitive are Malaysia's bilateral trade flows to depreciation? Applied Economics, v. 38, n. 11, p. 1279-1286, 2006.

BAHMANI-OSKOOEE, M.; HARVEY, H. J-curve: Singapore versus her major trading partners. Economic Papers: A journal of applied economics and policy, v. 31, n. 4, p. 515-522, 2012.

BAHMANI-OSKOOEE, M. et al.; KANTIPONG, T. Bilateral J-curve between Thailand and her trading partners. Journal of Economic Development, v. 26, n. 2, p. 107-118, 2001.

BAHMANI-OSKOOEE, M.; WANG, Y. The J curve: China versus her trading partners. Bulletin of Economic Research, v. 58, n. 4, p. 323-343, 2006.

BUSTAMANTE, R.; MORALES, F. Probando la condición de Marshall-Lerner y El efecto Curva-J: Evidencia empírica para el caso peruano. BANCO CENTRAL DE RESERVA DEL PERÚ, Estudios Economicos, n. 16, p.119-126, 2009.

FRANKEL, J. A.; CAVES, R. E.; JONES, R. W. Economia Internacional: Comércio e transações globais. 8. ed. São Paulo: Saraiva, 2001.

KYOPHILAVONG, P.; SHAHBAZ, M.; UDDIN, G. S. Does J-curve phenomenon exist in case of Laos? An ARDL approach. Economic Modelling, v. 35, p. 833-839, 2013.

LOBO, F. S. F. Análise empírica da existência do fenômeno da Curva J para a economia brasileira. Programa de Pós-Graduação em Economia. São Paulo, 2007.

MAGEE, S. P. Currency contracts, pass-through, and devaluation. Brookings Papers on Economic Activity, v. 1973, n. 1, p. 303-325, 1973.

MENDES, I. S.; PIZA, C. C. T. A relação entre a taxa de câmbio e a balança comercial: Um teste empírico sobre a Curva J no comércio bilateral Brasil - EUA. Revista Jovens Pesquisadores, ano IV, n.7, jul./dez. 2007. 
MOURA, G.; DA SILVA, S. Is There a Brazilian J-Curve? Economics Bulletin, v. 6, n. 10, 2005.

NARAYAN, P. K. New Zealand's trade balance: evidence of the J-curve and granger causality. Applied Economics Letters, v. 11, n. 6, p. 351-354, 2004.

PENA, H. W. A. et al. Modelagem cambial e os efeitos histerese e curva "j": uma aplicação na economia brasileira no período de 1992 a 2003. Observatorio de la Economía Latinoamericana, n. 154, 2011.

PESARAN, M. H.; SHIN, Y.; SMITH, R. J. Testes limites abordagens para a análise do nível de relacionamento. Journal of Econometrics Aplicada, 16, p. 289-326,2001.

ROSE, A. K.;YELLEN, J. L. Is there a J-Curve? Journal of Monetary Economics, 24, p. 53-68, July1989.

SHAHBAZ, M.; AWAN, R. U.; AHMAD, K. The exchange value of the Pakistan rupee \& Pakistan trade balance: An ARDL bounds testing approach. The Journal of Developing Areas, v. 44, n. 2, p. 69-93, 2011.

SHAHBAZ, M.; JALIL, A.; ISLAM, F. Real exchange rate changes and the trade balance: The evidence from Pakistan. The International Trade Journal, v. 26, n. 2, p. 139-153, 2012.

SOLEYMANI, A.; SABOORI, B. The J-curve: Evidence from commodity trade between Malaysia and Japan. The Internacional Journal of Applied Economics and Finance, v.6, n.2, p. 64-73, 2012

SONAGLIO, C. M.; SCALCO, R. P.; CAMPOS, A. C. Taxa de câmbio e balança comercial brasileira de manufaturados: Evidências da J-Curve. Revista Economia, Brasília (DF), v.11, n.3, p. 711-734, set./dez. 2010.

VASCONCELOS, C. R. F. Dinâmica de curto e longo prazo da balança comercial: A validade da hipótese da Curva-J. Programa de Pós-Graduação em Economia Aplicada - FE/UFJF. Jul./2010.

WANG, C.; LIN, C. A.; YANG, C. Japan and the World Economy, p. 266-273, 2012.

WIJEWEERA, A.; DOLLERY, B. J-curve disparity between the goods sector and the services sector: evidence from Australia. Applied Economics Letters, v. 20, n. 5, p. 452-456, 2013.

WILSON, P. Exchange rates and the trade balance for dynamic Asian economies-does the J-curve exist for Singapore, Malaysia, and Korea? Open Economies Review, v. 12, n. 4, p. 389-413, 2001.

WOOLDRIDGE, J. M. Econometric analysis of cross section and panel data. MIT press, 2010.

\section{Sobre os autores}

Hélio Sousa Ramos Filho - helioramos@gmail.com

Universidade Federal da Paraíba, João Pessoa, PB.

Maysa Evellyn Porfírio Ferreira - maysaevellyn@gmail.com

Universidade Federal da Paraíba, João Pessoa, PB.

\section{Sobre 0 artigo}

Recebido em 28 de maio de 2014. Aprovado em 31 de agosto de 2015. 